\title{
The effect of estradiol valerate with and without oral sildenafil on endometrial thickness and pregnancy rates in infertile women: A R.C.T
}

Original Article

\author{
Mohamed Ashraf Mohamed Farouk Kortam, Hayam Fathy Mohammad, Mostafa \\ Hassanein Mobarak and Abdalla Ahmed Ibrahim Bazazo
}

Obstetrics and Gynecology Department, Faculty of Medicine, Ain Shams Universityt

\begin{abstract}
Objective: Clomiphene citrate (CC) has some negative effects on the endometrium. We evaluated the effect of concomitant administration of oral sildenafil and estrogen on endometrial thickness (ET), pattern and pregnancy rates in CC stimulated cycles in infertile women diagnosed as unexplained infertility.

Aim of the Work: Compare the effect of sildenafil ᄀ-estrogen combination to estrogen alone on endometrium thickness in infertile women.

Materials and methods: It is a randomized controlled trial on 90 infertile women with unexplained infertility; patients were randomly divided into two equal groups. In control group, 45 patients were given ovulation induction with CC $100 \mathrm{mg} / \mathrm{d}$ from $2 \mathrm{nd}$ to 6 th day of cycle and oral estradiol valerate $2 \mathrm{mg} 12$ hourly from 2 nd day of the cycle till the day of trigger of ovulation. In study group, 45 patients were given ovulation induction with CC100mg/d from 2 nd to 6 th day of cycle, estradiol valerate $2 \mathrm{mg} 12$ hourly plus oral sildenafil citrate $25 \mathrm{mg}$ every $8 \mathrm{~h}$ from $2 \mathrm{nd}$ day of the cycle till the day of hCG trigger. A transvaginal ultrasound was performed on day 10 to assess follicular growth until the detection of at least one dominant follicle $\geq 18 \mathrm{~mm}$. At that time, the endometrium was evaluated as regards both endometrial thickness and pattern. Uterine artery resistive index (RI) was then measured. Qualitative serum B-hCG level was checked 14 days after ovulation to assess chemical pregnancy rate.

Results: Mean endometrial thickness at the time of hCG trigger was $9.8 \mathrm{~mm}$ in study group and $8.42 \mathrm{~mm}$ in control group ( $p$ value $<0.001$ ). $88.9 \%$ patients given sildenafil had trilaminar endometrium whereas $29 \%$ patients without sildenafil had trilaminar endometrial pattern $(p$ value $=0.006)$. Mean uterine artery resistive index $(\mathrm{RI})$ after adding sildenafil was non-significantly lower among study group than among control group; the values were 0.66 and 0.72 , respectively $(\mathrm{P}=$ 0.078). Pregnancy rates in study group and control group were $17.8 \%$ and $11.1 \%$, respectively.

Conclusion: Sildenafil $\neg$-estrogen combination has a potent effect on improving the endometrium (thickness and pattern) in patients undergoing induction of ovulation by clomiphene citrate. This improvement in endometrial development has a weak positive feedback on pregnancy rate.
\end{abstract}

Key Words: Endometrial Thickness - Estradiol Valerate - Pregnancy - Sildenafil.

Received: 10 September 2018, Accepted: 5 October 2018

Corresponding Author: Abdalla Ahmed Ibrahim Bazazo, Obstetrics and Gynecology Department, Faculty of Medicine, Ain Shams University, Tel.: +20 1000575081, E-mail: Abdalla_bazazo@med.asu.edu.eg

ISSN: 2090-7265, November 2018, Vol.8, No. 4

\section{INTRODUCTION}

The endometrium as a dynamic tissue can respond to the hormonal signals change throughout the cycle. The variations of the endometrial composition are related to the alternation in gene expression, the change in the secretion of the protein and hormone as well as the change of the micro architectural morphology. The combination of these factors together forms a "window of implantation" for a short time period during the luteal phase as the endometrium is becoming receptive $\mathrm{e}^{[1]}$.

Embryo implantation process is controlled by the interaction of various maternal and embryonic factors which consequently lead to the blastocyst adherence to the endometrium. Therefore, this process is a well-orchestrated and very delicate process ${ }^{[2]}$.

Thin endometrium is associated with a low pregnancy rate. During the pre-ovulatory phase, endometrial thickness of $7 \mathrm{~mm}$ is widely agreed to be the cut-off for the thin endometrium $^{[3]}$. Another study mentioned other cut-offs to be in the range of $58-\mathrm{mm}^{[4]}$. Moreover, several researchers found that a higher rate of pregnancy, with blastocyst stage embryo transfer, was achieved with endometrial thickness above $9 \mathrm{~mm}^{[5]}$.

Several factors affect the endometrium thickness like the reproductive age, the menstrual cycle phase, 
the concentration of ovarian hormone (estrogen and progesterone), and the density of endometrial hormone receptor ${ }^{[6]}$.

Being a hormone dependent tissue, the endometrium proliferates in response to estrogen which further induces the production of progesterone receptors. As a result, infertile patients who demonstrated thin endometrium were offered estradiol (E2) remedies in an attempt to improve endometrial proliferation. Most of the studies regarding E2 treatment in patients with thin endometrium dealt with frozen-thawed embryo transfer cycles. Moreover, there are several routes and durations of administration of E2 including per Os, transdermal, vaginal and intramuscular. With respect to pregnancy rates, there is not a compelling advantage for any endometrial preparation protocol over another ${ }^{[7]}$.

Clomiphene, a selective estrogen receptor modulator (SERM), with estrogen agonist and antagonist characteristics was used to stimulate the ovulation for the patients who experienced ovulatory dysfunction and chronic oligo-anovulation. Clomiphene citrate representing a competitive antagonist of $17 \beta$ estradiol competes with endogenous estrogen for nuclear estrogen receptors at different sites throughout the body. Although the ovulation rates are good, clomiphene has anti-estrogenic effects on the endometrium which in turn causes suboptimal pregnancy rate. Moreover, clomiphene exerts alongside desirable central actions, less desirable effects of antiestrogenic at peripheral sites of the reproductive system ${ }^{[8]}$.

Several researchers showed that administering estrogen with or after clomiphene prevented the $\mathrm{CC}$ adverse effects on endometrium. In the present study, to counteract clomiphene anti-estrogenic effects on endometrium, estrogen supplementation was introduced during the proliferative phase in $\mathrm{CC}$ induced cycles.

Sildenafil is considered a type 5-specific phosphodiesterase inhibitor; therefore, it increases the nitric oxide vasodilatory effects through the degradation prevention of cGMP. Vascular smooth muscle is relaxed during a cGMP-mediated pathway by Nitric oxide (NO) and NO synthase isoforms is found in the uterus. Some researchers studied the vaginal sildenafil effect on the thickness of endometrial of infertile patients who underwent IVF treatment and suffered from poor endometrial development. They showed an improvement in the flow of uterine artery blood and in the endometrial growth with higher implantation and ongoing pregnancy rates following vaginal sildenafil administration ${ }^{[9]}$.

As CC has some negative effects on the endometrium, the purpose of this study is to evaluate the effect of concomitant administration of oral sildenafil and estrogen on endometrial thickness (ET), pattern and pregnancy rates in CC stimulated cycles in infertile women diagnosed as unexplained infertility.

\section{AIM OF THE WORK:}

Compare the effect of sildenafil $\neg$-estrogen combination to estrogen alone on endometrium thickness in infertile women.

\section{MATERIALS AND METHODS}

The present study was a randomized controlled trial which was approved by the local Ethical and Research Committee, Ain-Shams University, Cairo, Egypt. It was conducted at the Infertility Outpatient Clinic in AinShams University Maternity Hospital during the period from October 2017 to May 2018. One hundred and seven patients diagnosed as unexplained infertility recruited from outpatient infertility clinic, ninety patients were fulfilling inclusion and exclusion criteria. The inclusion criteria were as follows: ${ }^{[1]}$ Patients with ovulatory cycles, ${ }^{[2]}$ Age between 1835- years and ${ }^{[3]}$ Body mass index (BMI) less than $30 \mathrm{~kg} / \mathrm{m} 2$.

The exclusion criteria were ${ }^{[1]}$ Presence of any organic lesion of uterus, ovaries or tubes such as endometrial polyps, leiomyomas and ovarian cysts. ${ }^{[2]}$ Patients who have any contraindication to medication ${ }^{[3]}$ Women have male factor for infertility. Patients incorporated in the study were randomly allocated into 2 equal groups using a randomized computer number generation by the closed envelope method. Patients eligible for the study have signed a written informed consent and were subjected to complete history taking with special stress on history of infertility. Physical examinations including general, abdominal and vaginal examinations were done, in addition to reviewing the patients' medical record including the result of HSG and/or hysteroscopy or laparoscopy reports plus hormonal analysis and semen analysis. Also, day 3 transvaginal ultrasound (Samsung H60 vag. Probe 49- MHZ covey 28-=MHZ) was performed for all patients eligible for the study at Ain-Shams Fetomaternal Ultrasound Unit. Group I (control group including 45 women) received clomiphene citrate (clomid 50mg ${ }^{\circledR}$, Sanofi aventis) 2 tab. single dose orally from the 2 nd day of the cycle for 5 days with oral estradiol valerate (Cyclo-Progynova ${ }^{\circledR} 2 \mathrm{mg}$, white tablets, BAYER Schering Pharma) one tablet every 12 hour from $2^{\text {nd }}$ day of the cycle till the day of trigger of ovulation. While, Group II (study group including 45 women) received clomiphene citrate 2 tab. single dose orally from the 2 nd day of the cycle for 5 days with oral estradiol valerate $2 \mathrm{mg}$, one tablet every 12 hour from 2 nd day of the cycle Additionally, sildenafil (Silden ${ }^{\circledR} 25$, E.I.P.I.CO.) was given every 8 hour from 2 nd day of the cycle till the day of trigger of ovulation.

Transvaginal U/S folliculometry began to be performed on day 10 every other day of the cycle until time of trigger for all patients incorporated in the study. During the procedure, endometrial thickness was measured (maximum distance 
between each myometrial/endometrial interface through the longitudinal axis of the uterus). Also, endometrial luminarity was recognized whether bi or trilaminar. Using 2D Doppler, uterine artery flow velocity was assessed from the ascending main branch of the uterine artery on the day of trigger. Triggering of ovulation was done by hCG (Epifasi ${ }^{\circledR}$ 5000IU. E.I.P.I.CO.) IM injection single dose. Timed intercourse was scheduled to be 3436- hours after the trigger of ovulation; luteal phase was supported by oral progesterone starting from day of ovulation for 14 days in the form of (Duphaston ${ }^{\circledR}, 10 \mathrm{mg}$, Solvay) one tablet every 12 hours. Qualitative serum B-hCG levels were checked 14 days after ovulation to assess chemical pregnancy rate at Clinical Pathology Department, AinShams University. Three primary outcomes (endometrial thickness, endometrial pattern and uterine artery blood flow) and chemical pregnancy rate per cycle as only secondary outcome.

\section{Statistical analysis}

The collected data were coded, tabulated and statistically analyzed using IBM SPSS version 18 software (Chicago, IL, USA). Descriptive statistics were done for quantitative data as minimum and maximum of the range as well as mean $\pm \mathrm{SD}$ (standard deviation) for quantitative normally distributed data; while, it was done for qualitative data as number and percentage. Inferential analyses were done for quantitative variables using Shapiro-Wilk test for normality testing, independent t-test in cases of two independent groups with normally distributed data. In qualitative data, inferential analyses for independent variables were done using Chi square test for differences between proportions. The level of significance was taken at $P$ value $<0.050$ is significant.

\section{RESULT}

(Figure 1) shows that ninety patients were divided in 2 equal groups. The study group included 45 women who received clomiphene citrate, estradiol valerate and sildenafil; while the control group included 45 women who received clomiphene citrate and estradiol valerate.

Table (1) shows that there was no statistically significant difference $(\mathrm{P}>0.05)$ between the studied groups as regard.
Table 1: Patient characteristics among the studied groups

\begin{tabular}{|c|c|c|c|}
\hline Variables & $\begin{array}{l}\text { Study } \\
(\mathrm{N}=45)\end{array}$ & $\begin{array}{l}\text { Control } \\
(\mathrm{N}=45)\end{array}$ & $\begin{array}{c}\mathrm{P}- \\
\text { value }\end{array}$ \\
\hline Age (years) & $27.2 \pm 4.0$ & $28.7 \pm 4.0$ & ${ }^{\wedge} 0.081$ \\
\hline BMI (kg/m2) & $26.6 \pm 1.4$ & $26.6 \pm 1.8$ & $\wedge 0.392$ \\
\hline Duration of infertility (years) & $2.7 \pm 1.0$ & $3.1 \pm 1.1$ & $\wedge^{\wedge} 0.118$ \\
\hline \multirow{2}{*}{$\begin{array}{c}\text { Type of } \\
\text { infertility (n, \%) }\end{array}$} & and $30(66.7 \%)$ & and $23(51.1 \%)$ & \multirow{2}{*}{$\# 0.364$} \\
\hline & and $15(33.3 \%)$ & and $22(48.9 \%)$ & \\
\hline FSH (mIU/ml) & $6.8 \pm 1.5$ & $7.0 \pm 1.3$ & $\wedge 0.522$ \\
\hline LH (mIU/ml) & $5.6 \pm 1.6$ & $5.8 \pm 1.5$ & $\wedge^{\wedge} 0.569$ \\
\hline Prolactin (ng/ml) & $12.6 \pm 5.0$ & $12.3 \pm 4.8$ & $\wedge^{\wedge} 0.787$ \\
\hline $\mathrm{E} 2(\mathrm{pg} / \mathrm{ml})$ & $54 \pm 9.8$ & $57.1 \pm 10.5$ & $\wedge 0.201$ \\
\hline TSH(iu/ml) & $1.82 \pm 0.34$ & $1.85 \pm 0.45$ & $\wedge 0.729$ \\
\hline
\end{tabular}

Values are mean \pm standard deviation (SD) or andn (\%)

Test used is $\wedge^{\wedge}$ Independent $\mathrm{t}$-test \#Chi square test
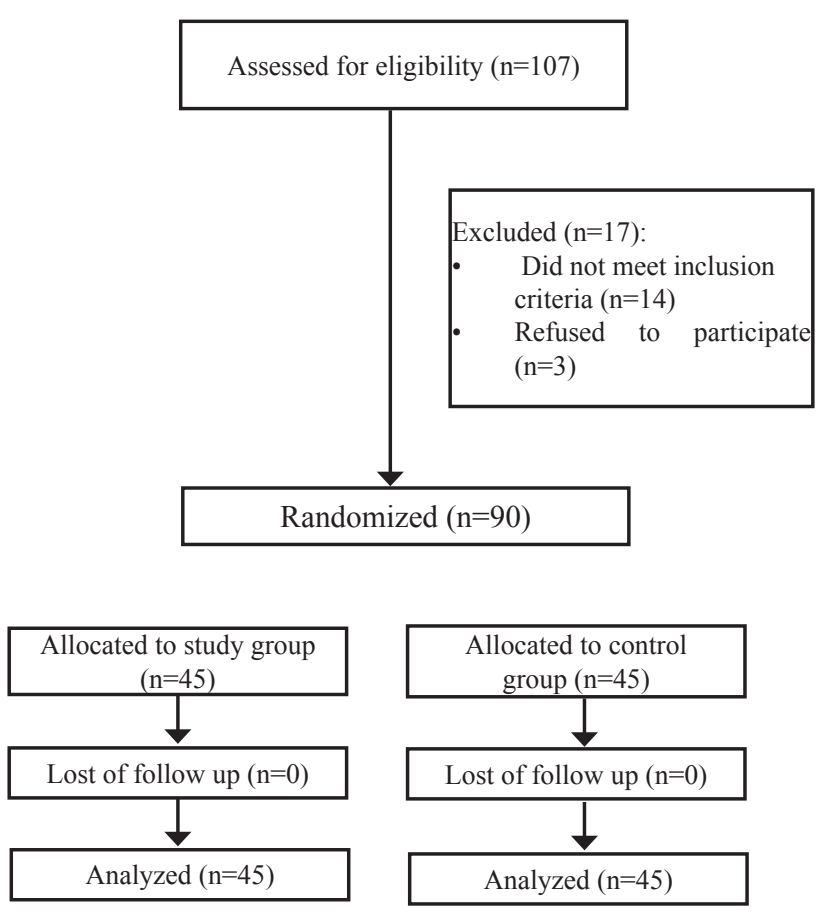

Fig. 1: Algorithm of patient's distribution

The mean uterine artery resistive indices (RI) among the studied groups on the day of trigger was non- 
significantly lower than the control group $(0.66 \pm 0.17$ vs. $0.72 \pm 0.15, \mathrm{p}=0.078$ ). However, table (2) shows that endometrial thickness in the studied group was highly significantly increased compared to the control group on day of trigger $(9.8 \pm 1.7$ vs. $8.4 \pm 1.2, \mathrm{p}=<0.00)$. Whereas, there was no statistically significant difference between study and control groups regarding basal endometrial thickness $(\mathrm{p}=0.532)$. Trilaminar pattern of endometrium was present more in the study group than the control group with the difference being highly statistically significant as shown in table (2).

Table 2: comparison of outcomes between the studied groups

\begin{tabular}{|c|c|c|c|}
\hline & Study $(\mathrm{N}=45)$ & Control $(\mathrm{N}=45)$ & P-value \\
\hline $\begin{array}{l}\text { Endometrial thickness on } \\
\text { day } 3 \text { of the cycle }(\mathrm{mm}) \\
\text { Mean } \pm \text { SD. }\end{array}$ & $5.5 \pm 1.0$ & $5.3 \pm 0.8$ & $\wedge 0.532$ \\
\hline $\begin{array}{l}\text { Endometrial thickness on } \\
\text { day of trigger }(\mathrm{mm}) \text {. Mean } \\
\pm \text { SD. }\end{array}$ & $9.8 \pm 1.7$ & $8.4 \pm 1.2$ & $\wedge<0.001^{*}$ \\
\hline $\begin{array}{l}\text { Net increase in endometrial } \\
\text { thickness }(\mathrm{mm}) \text { Mean } \pm \text { SD. }\end{array}$ & $4.3 \pm 1.3$ & $3.0 \pm 1.1$ & $\wedge<0.001^{*}$ \\
\hline $\begin{array}{l}\text { Endometrial pattern } \\
\text { Trilaminar (n, \%) } \\
\text { Bilaminar (n, \%) }\end{array}$ & $\begin{array}{l}40(88.9 \%) \\
5(11.1 \%)\end{array}$ & $\begin{array}{l}29(64.4 \%) \\
16(35.6 \%)\end{array}$ & $\# 0.006^{*}$ \\
\hline $\begin{array}{l}\text { Uterine artery resistive } \\
\text { indices (RI) on day of } \\
\text { trigger. Mean } \pm \mathrm{SD}\end{array}$ & $0.66 \pm 0.17$ & $0.72 \pm 0.15$ & $\wedge 0.078$ \\
\hline $\begin{array}{l}\text { Chemical pregnancy rate } \\
\text { Present (n, \%) } \\
\text { Absent (n, \%) }\end{array}$ & $\begin{array}{c}8(17.8 \%) \\
37(82.2 \%)\end{array}$ & $\begin{array}{c}5(11.1 \%) \\
40(88.9 \%)\end{array}$ & $\wedge 0.368$ \\
\hline
\end{tabular}

Values are presented as mean \pm standard deviation or $\mathrm{n}(\%)$.

Test used is ${ }^{\wedge}$ Independent t-test, Test used is \#Chi square test, *Significant.

Eight patients out of forty-five in the study group were serum B-hCG positive, whereas five patients out of fortyfive in the control group were serum B-hCG positive but still the results were non-significant $(\mathrm{p}=0.368)$.

\section{DISCUSSION}

Clomiphene citrate is a very commonly used ovulation inducing agent. However, it has no role in couples where the female partner has a regular menstrual cycle. Fahmy et al. ${ }^{[10]}$ reported that despite the good rates of ovulation with CC many, patients still do not achieve pregnancy due to implantation failure. Mishra et al. ${ }^{[11]}$ also reported that implantation is the weakest link for the success of any assisted reproductive technique with endometrial receptivity as the crucial necessity for implantation. Steroid hormones, growth factors and cytokines regulated endometrial development. Some of the regulatory factors are produced locally and others have to be transferred to the endometrium for which sufficient blood supply is required. The results of the present study were compared to previous studies. In a prospective study by Takasaki et al., out of 61 patients with a thin endometrium $(8 \mathrm{~mm})$, there was a significant improvement in endometrial thickness, eleven patients $(92 \%)$ showed improved RA-RI $(<0.81)$ and endometrial thickness $(>8 \mathrm{~mm})$ after sildenafil citrate treatment ${ }^{[12]}$

The results of our study are in accordance with Fisch et al. who reported an increase in ET when used from day 8 to day $13^{[9]}$. Jerzak et al. ${ }^{[13]}$ reported that there is a good correlation between endometrial thickness and prevalence of conception and that ET greater than $9 \mathrm{~mm}$ as determined by vaginal ultrasound correlates well with pregnancy rate.

Other studies confirmed that the present findings, Alataş et al. showed that after the administration of a single oral dose of $50 \mathrm{mg}$ sildenafil citrate, the mean uterine arterial resistance index $(0.73 \pm 0.08)$ and pulsatility index $(1.66$ $\pm 0.50)$ were significantly lower ${ }^{[14]}$. Also, Hale et al. ${ }^{[15]}$ confirmed our findings regarding the effect of sildenafil. The study included 15 women over a two year period starting in May 2006 and ending in June 2008. Color Doppler ultrasound of both uterine arteries was performed at baseline and 1 and 3- hours post-dosing to calculate resistance index (RI) and UVF. Those who received sildenafil increased UVF significantly and decreased RI over the three hour monitoring period. The current study showed that trilaminar pattern of endometrium was present more frequent in the study group than the control group with the difference being highly statistically significant 40 (88.9\%), 29 (64.4\%), respectively $(\mathrm{P}<0.001)$.

The current study depicted that chemical pregnancy occurred more in the study group than control group, yet the difference was not statistically different $(\mathrm{P}>0.05)$.

This goes with the results of Fahmy et al. ${ }^{[10]}$ that showed non-statistical significant difference in pregnancy rate between both groups; the pregnancy rate in the treatment group was higher by 2.5 than the placebo group. This could be due to the small number of cases in their study and the non-significant difference in patient's demographics in both groups. Another reason is that the endometrium was significantly thicker on day of HCG in the sildenafil group. The thickness was within the acceptable range in both groups.

Ataalla et al. ${ }^{[16]}$ confirmed the present findings. This goes also with Firouzabadi et al., who showed that the oral use of sildenafil citrate can be a good way to improve endometrial receptivity and pregnancy rate.

\section{CONCLUSION}

Sildenafil $\neg$-estrogen combination has a potent effect on improving the endometrium (thickness and pattern) in patients undergoing induction of ovulation by clomiphene 
citrate. This improvement in endometrial development has a weak positive feedback on pregnancy rate.

\section{REFERENCES}

1. Casper RF and Yanushpolsky EH (2016): Optimal endometrial preparation for frozen embryo transfer cycles: window of implantation and progesterone support. Fertil Steril., 105(4): 867-872.

2. Paiva P, Hannan NJ, Hincks C, Meehan KL and Pruysers E (2011): Human chorionic gonadotrophin regulates FGF2 and other cytokines produced by human endometrial epithelial cells, providing a mechanism for enhancing endometrial receptivity. Hum Reprod, 26: 1153-62.

3. Wu Y, Gao X and Lu X (2014): Endometrial thickness affects the outcome of in vitro fertilization and embryo transfer in normal responders after GnRH antagonist administration. Reprod Biol Endocrinol, 12: 96.

4. Fang R, Cai L, Xiong F, Chen J, Yang W and Zhao X (2016): The effect of endometrial thickness on the day of hCG administration on pregnancy outcome in the first fresh IVF/ICSI cycle. Gynecol Endocrinol, 8: 1-4.

5. Richter KS, Bugge KR, Bromer JG and Levy MJ (2007): Relationship between endometrial thickness and embryo implantation, based on 1,294 cycles of in vitro fertilization with transfer of two blastocyst-stage embryos. Fertility and Sterility, 87(1): 53-9.

6. Paulson RJ (2011): Hormonal induction of endometrial receptivity. Fertil Steril.. 96: 530-535.

7. Groenewoud ER, Cantineau AEP and Kollen BJ (2013): What is the optimal means of preparing the endometrium in frozen-thawed embryo transfer cycles. Asystematic review and meta analysis. Hum Reprod Update, 19: 458-470.

8. Gupta S, Tempe A and Sahu L (2014): Supplementation with estradiol valerate and gonadotropins in clomiphene citrate stimulated IUI cycles. Int. J. Biomed. Adv. Res.. 5(4): 211-4.
9. Fisch JD and Sher G (2002): Effect of vaginal sildenafil on the outcome of in vitro fertilization (IVF) after multiple IVF failures attributed to poor endometrial development. Fertil Steril, 78: 1073-1076.

10. Fahmy AA, ElSokkary M and Sayed S (2015): The value of oral sildenafil in the treatment of female infertility: A Randomised controlled trial. Life Sci J., 12(4): 78-82.

11. Mishra VV, Choudhary S and Bandwal P (2015): Vaginal Sildenafil: Role in improving endometrial blood flow in women undergoing IVF with frozen thawed embryo cycles. IJSR., 4(8): 292-4.

12. Takasaki A, Tamura H, Miwa I, Taketani T, Shimamura $\mathrm{K}$ and Sugino N (2010): Endometrial growth and uterine blood flow: a pilot study for improving endometrial thickness in the patients with a thin endometrium. Fertil Steril., 93(6): 1851-8.

13. Jerzek M, Kniotek M and Mrozek J (2008): Sildenafil citrate decreased natural killer cell activity and enhanced chance of successful pregnancy in women with history of recurrent miscarriage. Fertil Steril., 90: $1848-1853$

14. Alataş E and Yağci AB (2004): The Effect of Sildenafil Citrate on Uterine and Clitoral Arterial Blood Flow in Postmenopausal Women. Medscape General Medicine, 6(4): 51.

15. Hale SA, Jones CW, Osol G, Schonberg A, Badger GJ and Bernstein IM (2010): Sildenafil increases uterine blood flow in nonpregnant nulliparous women. Reproductive Sciences, 17(4): 358-65.

16. Ataalla WM, Abd Elhamid $\mathrm{T}$ and Elhalwagy $\mathrm{AE}$ (2016): Adjuvant sildenafil therapy in poor responders undergoing in vitro fertilization: A prospective, randomized, double-blind, placebo-controlled trial. Middle East Fertility Society Journal, 21(3): 175-9. 